\title{
Sulfur Dioxide and Volatile Organic Compound Exposure to a Community in Texas City, Texas Evaluated Using Aermod and Empirical Monitoring Data
}

\author{
Joyce A. Chen, Andrew R. Zapata, Anders J. Sutherland, David R. Molmen, \\ Brittany S. Chow, Lauren E. Wu, Paul E. Rosenfeld and Rob C. Hesse
}

Soil Water Air Protection Enterprise, 1640 5th Street, Suite 204, Santa Monica, CA 90401, USA

\begin{abstract}
According to emissions data reported to the United States Environmental Protection Agency (USEPA) and the Texas Commission on Environmental Quality (TCEQ), the BP Products North America Inc. (BP) Texas City Refinery is the worst polluter of all the industries in Texas City and is one of the worst polluting refineries in the country. The facility has reported releasing substantial emissions of Sulfur Dioxide (SO2) and Volatile Organic Compounds (VOCs). Air dispersion modeling of the emissions from the facility can be used to assess contamination in the community surrounding the BP Texas City Refinery. In the present study, air dispersion modeling of SO2 and VOCs was performed using AERMOD, the EPA-preferred regulatory dispersion model, to determine the impact of BP's contribution to local air pollution on residents of Texas City and La Marque. SO2 emissions reported to be released by the facility were modeled using AERMOD and it was determined that geographical locations inside this plume experienced ambient air concentrations of SO2 meeting or exceeding 50 micrograms per cubic meter $\left(\mu \mathrm{g} / \mathrm{m}^{3}\right)$ in 2009 and 2010. Data collected by six active SO2 air monitors located in Texas City support the air dispersion modeling results. Additional modeling was conducted for VOCs emitted by the facility in 2010. The AERMOD analysis of SO2 concentrations in and around the BP facility produced results consistent with data collected by the air monitoring network in Texas City. This confirms the accuracy of AERMOD's estimations and its reliability as an emissions modeling tool. VOC concentrations available for analysis from the air monitoring network in Texas City are extremely limited in terms of the quantity of VOCs sampled for. This evidence affirms the ability of AERMOD to demonstrate comprehensive contaminant impacts that surpass the ability of the current air monitoring network.
\end{abstract}

Keywords: AMS/EPA Regulatory Model, AERMOD, Air Monitoring, BP, Emissions, Refinery

\section{INTRODUCTION}

The BP Products North America Inc. (BP) Texas City Refinery is an oil refinery that has been in operation since 1998. The surrounding communities of Texas City and La Marque are located primarily to the west, northwest, north and northeast of the BP facility. The geographic location of Texas City near Galveston Bay, with its high precipitation and humidity, is conducive to the acceleration of chemical processes in the atmosphere. Texas City is also located in a county with nonattainment status for ozone.

The BP Texas City Refinery emits large quantities of atmospheric pollutants and has an extensive history of poor operational performance, including upsets, excessive emissions events, violations and accidents. The BP Texas City Refinery is the largest polluter in the Texas City area and emits large quantities of Criteria Air

Corresponding Author: Andrew R. Zapata, Soil Water Air Protection Enterprise, 1640 5th Street, Suite 204, Santa Monica, CA 90401, USA 
Joyce A. Chen et al. / American Journal of Environmental Science 8 (6) (2012) 622-632

Pollutants (CAPs) and Hazardous Air Pollutants (HAPs), including, but not limited to Sulfur Dioxide (SO2), Volatile Organic Compounds (VOCs), Nitrogen Oxides (NOx) and Particulate Matter (PM). Compared to other industries in Galveston County, the BP Refinery releases atmospheric pollutants in amounts many times greater than other facilities. Figure 1-4 depict BP's contributions to $\mathrm{SO} 2$ and VOC pollution in Galveston County. The BP Texas City Refinery contributes a significant portion of $\mathrm{SO} 2$ and $\mathrm{VOC}$ emissions in Galveston County in 2009 and 2010. Based on total air emissions reported to the United States Environmental Protection Agency (USEPA) Toxics Release Inventory (TRI), the BP Texas City Refinery reported more total toxic air emissions than any other refinery in 2009 and 2010 combined. Furthermore, the BP Texas City Refinery reported releasing more toxic air emissions per barrel of crude oil processed than the top ten largest refineries in the United States. A comparison of United
States refineries, including BP Texas City, can be seen in Table 1.

Sulfur Dioxide produces a variety of adverse respiratory effects, according to multiple authoritative agencies, including bronchoconstriction (narrowing of the airways leading to difficulty breathing), increased asthma symptoms and hospital admissions for respiratory illnesses (USEPA, 2009). The Agency for Toxic Substances and Disease Registry (ATSDR) also states that $\mathrm{SO} 2$ pollution is associated with respiratory symptoms and reduced breathing ability. Children who breathe SO2 pollution may develop more breathing problems and respiratory illnesses as they get older and may make more emergency room visits for respiratory illness (ATSDR, 1998). Respiratory effects in humans from SO2 have been demonstrated at ambient levels as low as $9 \mu \mathrm{g} \mathrm{m}^{-3}$ (3.46 ppb), averaged over several years (Fung et al., 2006) and $11 \mu \mathrm{g} \mathrm{m}^{-3}$ (4.27 ppb) averaged over 24 h (Chiu et al., 2009).
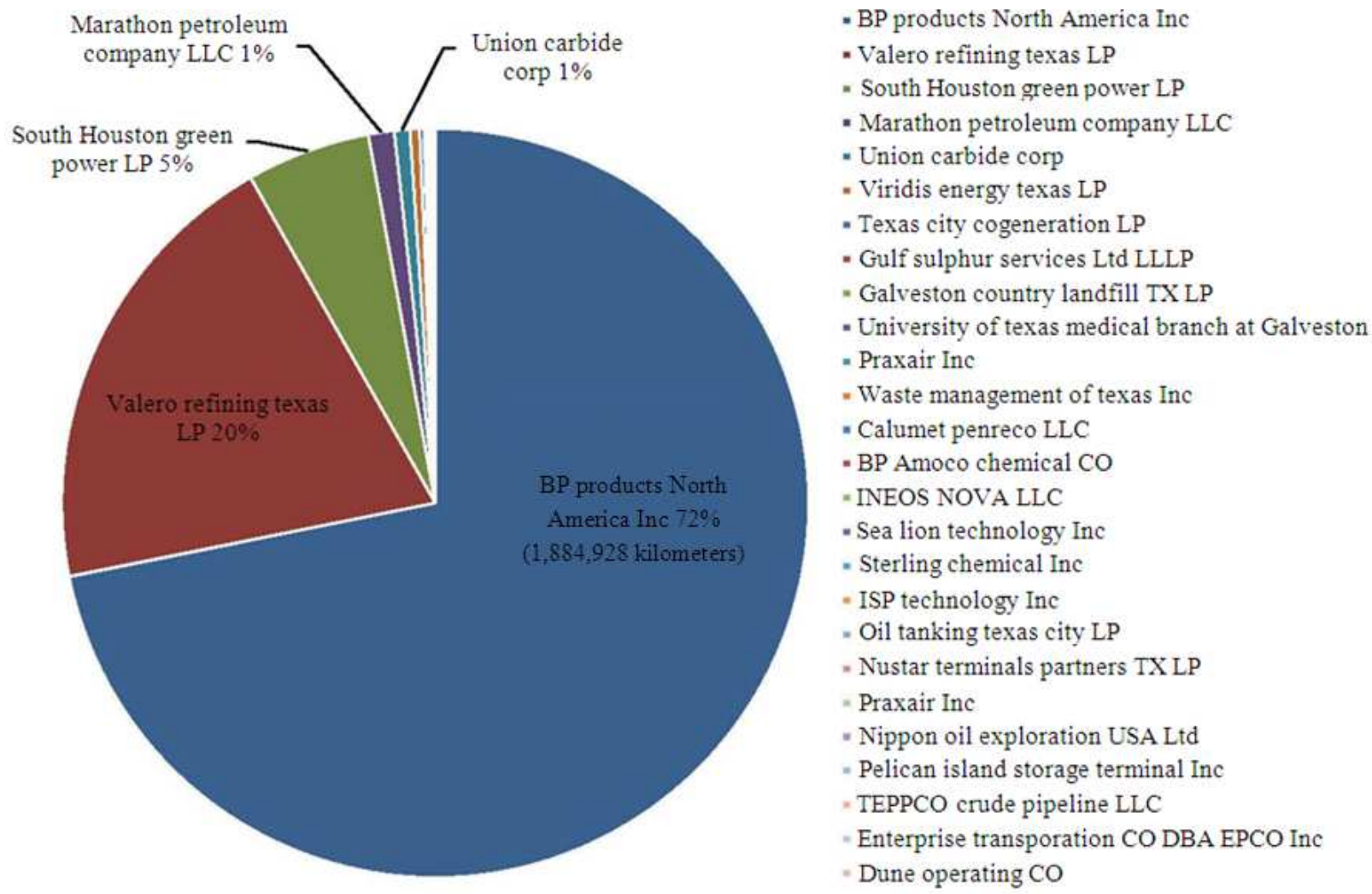

Note: All data obtained from TCEQ point source emission inventory web portal, state summary file: http:/www.tceq.texas.gov/airquality/point-source-el/psei.html

Fig. 1. Sulfur dioxide releases reported to the 2009 TCEQ emissions inventory in Galveston County 
Joyce A. Chen et al. / American Journal of Environmental Science 8 (6) (2012) 622-632

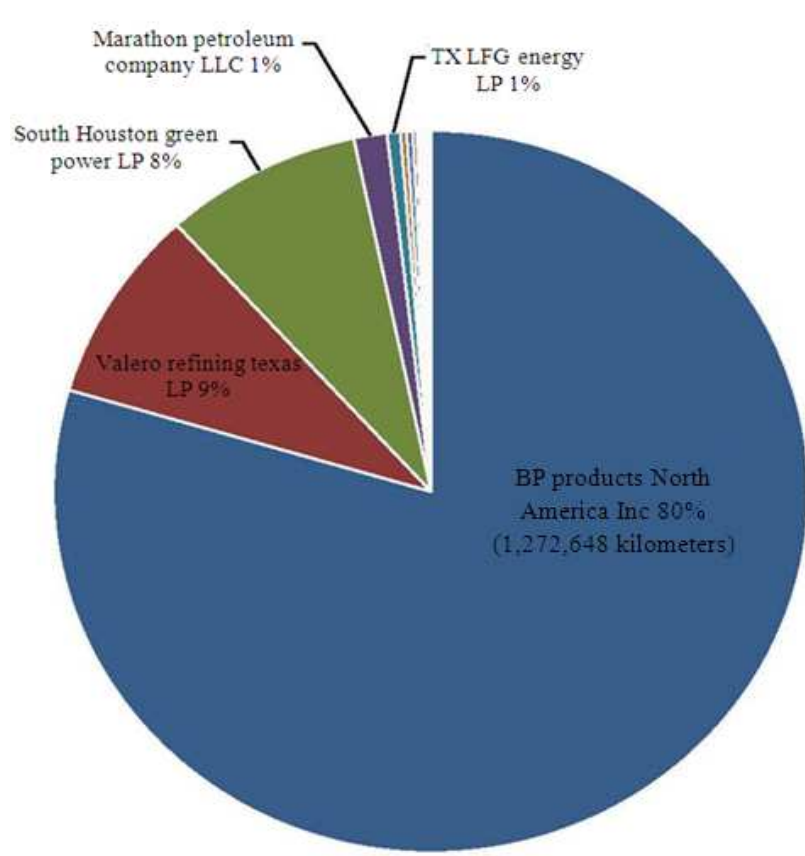

- BP products North America Inc

- Valero refining texas LP

- South Houston green power LP

- Marathon petroleum company LLC

- TX LFG energy LP

- Galveston country landfill TX LP

- Texas city cogeneration LP

- Gulf sulphur services Ltd LLLP

- Union carbide corp

- Waste management of texas Inc North texas

- University of texas medical branch at Galveston

- BP Amoco chemical CO

- Praxair Inc

- Nustar terminals partners TX LP

- INEOS styrenics LLC

- Sea lion technology Inc

- ISP technology Inc

- Sterling chemical Inc

- Calumet penreco LLC

- Oil tanking texas city LP

- HHE energy CO

- Praxair Ine

- Black ELK energy offshore operations LLC

- Pelican island storage terminal Inc

- Enterprise crude pipeline LLC

- Enterprise products transporation CO LLC

- Denbury onshore LLC

- Dune operating CO

HHE energy $C O$

- Hassie hunt exploration CO

Mark L shidler Inc

Note: All data obtained from TCEQ point source emission inventory web portal, state summary file: http://www.tceq.texas gov/airquality/point-source-el psei.html

Fig. 2. Sulfur dioxide releases reported to the 2010 TCEQ emissions inventory in Galveston County

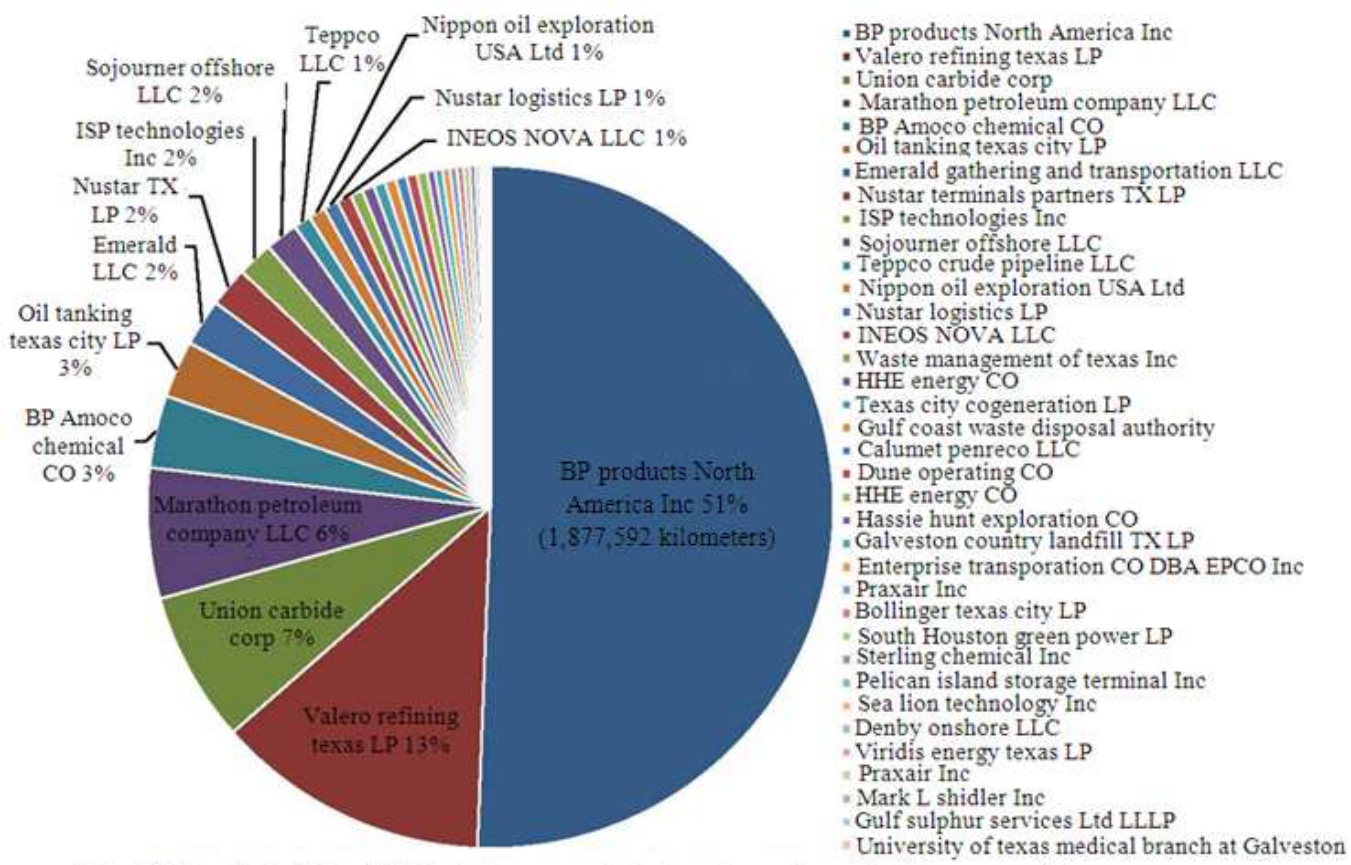

Note: All data obtained from TCEQ point source emission inventory web portal, state summary file:

http://www.tceq.texas.gov/airquality/point-source-el/psei.html

Fig. 3. Volatile organic compound releases reported to the 2009 TCEQ emissions inventory in Galveston County 


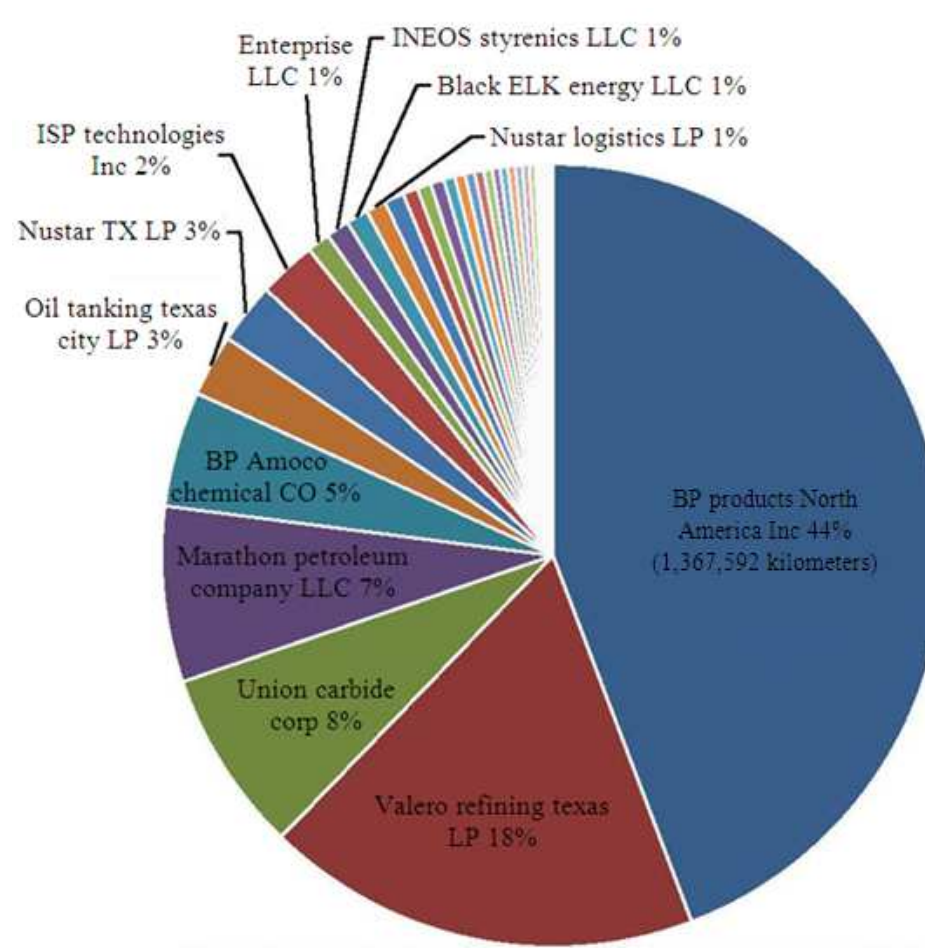

- BP products North America Inc

- Valero refining texas LP

- Union carbide corp

- Marathon petroleum company LLC

- BP Amoco chemical CO

- Oil tanking texas city LP

- Nustar terminals partners TX LP

- ISP technologies Inc

- Enterprise crude pipeline LLC

- INEOS styrenics LtC

- Black ELK energy offshore operations LLC

- Nustar logistics LP

" HHE energy CO

- Calumet penreco LLC

- Dune operating CO

- Texas city cogeneration LP

- Waste management of texas Inc North texas

" Enterprise products transportation CO LLC

- Praxair Inc

- Emerald gathering and transportation LLC

- South Houston green power LP

- Sterling chemical Inc

Hassie hunt exploration $\mathrm{CO}$

Denby onshore LLC

HHE energy CO

Gulf coast waste disposal authority

- Bollinger texas city LP

" TX LFG energy LP

" Sea lion technology Inc

Gulf sulphur services Ltd LLLP

Pelican island storage terminal Inc

Galveston country landfill TX LP

Praxair Inc

- Mark L shidler Inc

University of texas medical branch at Galveston

Note: All data obtained from TCEQ point source emission inventory web portal, state summary file:

http:/www.tceq.texas.gov/airquality point-source-el psei.html

Fig. 4. Volatile organic compound releases reported to the 2010 TCEQ emissions inventory in Galveston County

Table 1. Operable capacity and reported toxic air emissions at the largest refineries in the United States

\begin{tabular}{|c|c|c|c|c|c|c|c|c|c|}
\hline Rank & Corporation & Company name & State & Site & $\begin{array}{l}\text { Total operable } \\
\text { capacity } \\
\text { (Barrels per } \\
\text { calendar day) }\end{array}$ & $\begin{array}{l}2009 \\
\text { toxic air } \\
\text { Emissions }^{\mathrm{B}} \\
\text { (Pounds) }\end{array}$ & $\begin{array}{l}2010 \\
\text { toxic air } \\
\text { emissions } \\
\text { (Pounds) }\end{array}$ & $\begin{array}{l}\text { (Pounds) } \\
\text { Combined } \\
2009-2010 \\
\text { toxic air } \\
\text { emissions }\end{array}$ & $\begin{array}{l}\text { Ratio } \\
\text { of air } \\
\text { emissions } \\
\text { to operable } \\
\text { capacity }\end{array}$ \\
\hline 1 & Exxon Mobil Corp. & $\begin{array}{l}\text { ExxonMobil } \\
\text { refining and supply Co. }\end{array}$ & $\mathrm{TX}$ & Baytown & 560,640 & $1,089,687$ & $1,376,343$ & $2,466,030$ & 4.4 \\
\hline 2 & Exxon Mobil Corp. & $\begin{array}{l}\text { exxonmobil } \\
\text { refining and supply Co. }\end{array}$ & LA & Baton rouge & 504,500 & $1,261,817$ & $1,113,013$ & $2,374,831$ & 4.7 \\
\hline 3 & Hovensa LLC & Hovensa LLC & VI & Kingshill & 500,000 & 453,838 & 482,452 & 936,291 & 1.9 \\
\hline 4 & BP PLC & $\begin{array}{l}\text { BP Products North } \\
\text { America Inc., }\end{array}$ & $\mathrm{TX}$ & Texas city & 437,080 & $1,256,740$ & $1,258,597$ & $2,515,337$ & 5.8 \\
\hline 5 & Marathon Oil Corp. & $\begin{array}{l}\text { Marathon } \\
\text { petroleum Co LLC }\end{array}$ & LA & Garyville & 436,000 & 223,152 & 340,332 & 563,485 & 1.3 \\
\hline 6 & PDV America Inc. & Citgo Petroleum Corp. & LA & Lake charles & 429,500 & 913,958 & 571,637 & $1,485,595$ & 3.5 \\
\hline 7 & BP PLC & BP Products & IN & Whiting & 405,000 & 702,541 & 683,765 & $1,386,306$ & 3.4 \\
\hline 8 & WRB Refining LLC & $\begin{array}{l}\text { WRB Refining LLC } \\
\text { North America Inc., }\end{array}$ & IL & Wood river & 362,000 & 604,234 & 519,955 & $1,124,188$ & 3.1 \\
\hline 9 & Exxon Mobil Corp. & $\begin{array}{l}\text { Exxon mobil } \\
\text { refining and supply Co. }\end{array}$ & $\mathrm{TX}$ & Beaumont & 344,500 & 792,291 & 815,287 & $1,607,579$ & 4.7 \\
\hline 10 & Sunoco Inc. & Sunoco Inc (R and $M)$ & PA & Philadelphia & 335,000 & 535,803 & 600,329 & $1,136,132$ & 3.4 \\
\hline
\end{tabular}


Volatile Organic Compounds are also known to be harmful to human health (USEPA, 2010). Adverse respiratory effects resulting from VOC exposure include respiratory tract irritation and discomfort, dyspnea (debilitating shortness of breath) and epistaxis (nasal hemorrhage) (USEPA, 2012). Human studies demonstrate an association between VOC exposure and respiratory effects such as bronchitis, asthma and asthma-like symptoms, airway inflammation, general bronchial irritation and other chronic respiratory symptoms (Ware et al., 1993; Wieslander et al., 1997). Furthermore, when VOCs and NOx interact in the atmosphere in the presence of sunlight, they react to produce ozone, which causes serious respiratory problems (USEPA, 2010). VOCs released in large quantities by petroleum refineries such as the BP Texas City Refinery include, but are not limited to, Benzene, Toluene, Ethylbenzene, Xylene (BTEX) compounds that produce adverse effects in the respiratory system.

Schools evaluated within a one-mile radius of the facility in a 2009 USA Today study were found to be ranked among the worst schools for air quality in the United States. These schools were consistently in the first, second, or third percentile for schools with the worst air quality in the United States. At these schools, sulfuric acid and polycyclic aromatic hydrocarbons were the first and second most prevalent chemicals, responsible for roughly $40 \%$ and $30 \%$ of the toxicity respectively. Furthermore, the BP Texas City Refinery is listed as the primary polluter for eight schools in the first, second, or third percentile for schools with the worst air quality in the United States.

\section{MATERIALS AND METHODS}

Air dispersion modeling was performed using AERMOD, the USEPA preferred regulatory dispersion model, to estimate ambient air concentrations of SO2 and VOC concentrations in the surrounding community. AERMOD is a computer-based modeling system designed for short-range (up to $50 \mathrm{~km}$ ) dispersion of air pollutant emissions from stationary steady-state industrial sources developed by the American Meteorological Society/EPA Regulatory Model Improvement Committee. Meteorological and topographical data specific to the modeled area were input to AERMOD.

Pre-processed meteorological data specifically for the AERMOD system was obtained directly from Trinity Consultants. For this analysis, 2009 and 2010 surface data from Scholes Field in Galveston, Texas and upper air data from Lake Charles, Louisiana were used. Geospatial data used in the dispersion modeling analysis included sixteen United States Geological Survey Digital Elevation Models (DEMs). DEM data of the $7.5 \mathrm{~min}$ quadrangles covering the modeled area were obtained from MapMart Global Mapping Solutions.

Ground level receptors were defined using nested Cartesian receptor grids. Fine grids containing $500 \mathrm{~m}$ spacing were placed across the property line and extended approximately four to $5 \mathrm{~km}$ into the adjacent community. Coarse grids were overlain containing 1000 $\mathrm{m}$ spacing and extended approximately $15 \mathrm{~km}$ into the community. Receptors and geospatial data were compiled within the AERMAP preprocessor to obtain terrain elevations at receptor locations.

2009 and 2010 Annual Emissions Inventory (EI) data reported to Texas Commission on Environmental Quality (TCEQ) by BP were compiled and used for the modeling analysis. Data were obtained directly from the TCEQ Emissions Assessment Section. The EI contains unit-specific data such as stack diameter, stack height, exit stack gas temperature and exit stack gas velocity. Site-wide emissions for the Texas City Refinery can be quantified from these reported data to provide a baseline estimate of emissions into the community, assuming constant emissions rates and lack of interaction between pollutants. Modeling was performed to estimate SO2 and VOC emissions from site-wide processes at the refinery in 2009 and 2010.

To streamline the air modeling analysis, only emissions sources from the 2009 and 2010 EI's that were reported to emit greater than or equal to one ton of chemicals were compiled. Emissions sources that emitted greater than or equal to one ton of chemicals have been determined to account for the vast majority of emissions at the BP facility. The emissions data were joined with stack, flare and fugitive parameter data tables received from the TCEQ Emissions Assessment Section.

To verify source locations reported to the EI in the parameter data tables, they were plotted in ArcGIS with some manual corrections. Sources were relocated based on plot plans of the BP Refinery and Docks facilities received from TCEQ and aerial imagery. Sources that were not able to be accurately located were modeled at the center of the refinery. Verification of source locations allowed for a more accurate depiction of sitewide emissions from the facility.

Some emissions sources were missing parameters, such as stack height or velocity, in the 2009 and 2010 EI stack, flare and fugitive parameter data tables received 
from TCEQ. These emissions sources were assigned parameters based on data obtained from BP or from a similar unit. Emissions sources lacking unit-specific data were assigned nominal values.

AERMOD was used to model the $1 \mathrm{~h}$ concentrations of SO2 and VOCs based on releases reported at the BP facility in 2009 and 2010. AERMOD outputs were interpolated using the kriging algorithm in ArcGIS.

Results of air dispersion modeling of $1 \mathrm{~h}$ concentrations of $\mathrm{SO} 2$ and VOCs were then analyzed with corresponding air monitoring data. The air monitoring data was obtained through TCEQ and other agencies that operate a network of ambient air quality monitoring stations in the Texas City area. Compounds sampled for at air monitoring locations include NOx, Ozone and SO2. VOCs are monitored for through the use of $24 \mathrm{~h}$ SUMMA canister samples taken every six days at multiple air monitoring locations. Hourly VOC air monitoring data is only available for four compounds: Benzene, Toluene, Pentane and Hexane. These hourly samples are collected at three air monitoring locations: The Texas City Logan and 31st Street air monitors and the BP Onsite air monitor. VOC data from the aforementioned locations was only available for 2010 as the air monitoring stations were not active until 2010.

An important factor to note in the ability of air monitoring equipment to accurately and reliably sample for $\mathrm{SO} 2$ is observed through quenching. The USEPA states: "Nonradiative deactivation (quenching) of excited $\mathrm{SO} 2$ molecules can occur from collisions with common molecules in air, including nitrogen, oxygen and water. During collisional quenching, the excited SO2 molecule transfers energy, kinetically allowing the $\mathrm{SO} 2$ molecule to return to the original lower energy state without emitting a photon. Collisional quenching results in a decrease in the $\mathrm{SO} 2$ fluorescence and, hence, an underestimation of $\mathrm{SO} 2$ concentration in the air sample. Of particular concern is the variable water vapor content of air. Luke (1997) reported that the response of the detector could be reduced by an amount of $\sim 7$ to $15 \%$ at water vapor mixing ratios of 1 to 1.5 mole percent (Relative Humidity (RH) $=35$ to $50 \%$ at 20 to $25^{\circ} \mathrm{C}$ and 1 Atmosphere (ATM) for a modified pulsed fluorescence detector (Thermo Environmental Instruments, Model 43s))" (USEPA, 2008). Meteorological data from 2010 demonstrates that the observed relative humidity throughout Galveston County is consistently greater than $50 \%$. Relative humidity at this level would indicate a reasonable potential for a reduction in detector response for air monitoring equipment that samples for $\mathrm{SO} 2$.

\section{RESULTS AND DISCUSSION}

Figure 5 is based on emissions of $\mathrm{SO} 2$ from the BP facility in 2009 and 2010 that met or exceeded 50 micrograms per cubic meter $\left(\mu \mathrm{g} / \mathrm{m}^{3}\right)$ in ambient air in the Texas City and La Marque communities. Figure 6 depicts the extent of VOC emissions reported to be released by the BP facility in 2010 .

At each geographic location within the $\mathrm{SO} 2$ plume in Fig. 5, AERMOD predicted that BP's reported baseline releases were responsible for at least one increase of $50 \mu \mathrm{g} \mathrm{m}^{-3}$ in $1 \mathrm{~h}$ ambient SO2 concentrations in 2009 and 2010. The reasoning for using $50 \mu \mathrm{g} \mathrm{m}^{-3}$ of $\mathrm{SO} 2$ as the basis for the plume is based on two epidemiological studies demonstrating a statistically significant, more-than-doubled risk for the exposed population against the control population of developing the effect in question (Delfino et al., 2003; Segala et al., 1998). In order to establish this plume, modeled $1 \mathrm{~h} \mathrm{SO} 2$ concentration outputs for 2009 and 2010 were analyzed. Sensitive children subjected to these $\mathrm{SO} 2$ levels are expected to suffer asthma attacks or incidents of respiratory distress resulting from BP's hazardous emissions.

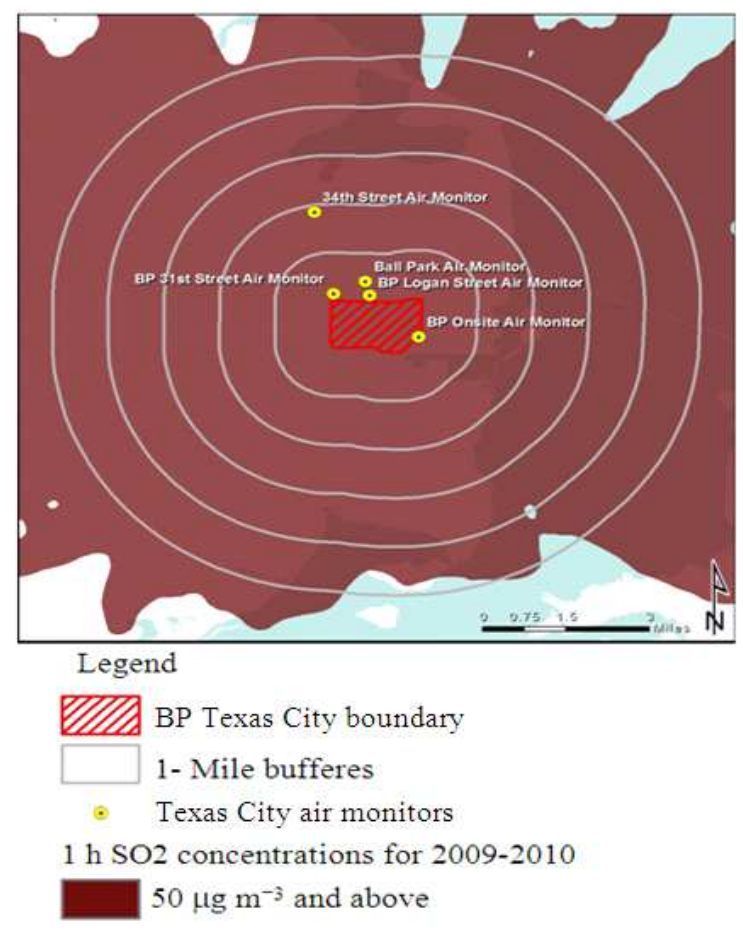

Fig. 5. 2009-2010 1-hour ambient air concentration of SO2 in Texas City based on BP Texas City emissions 


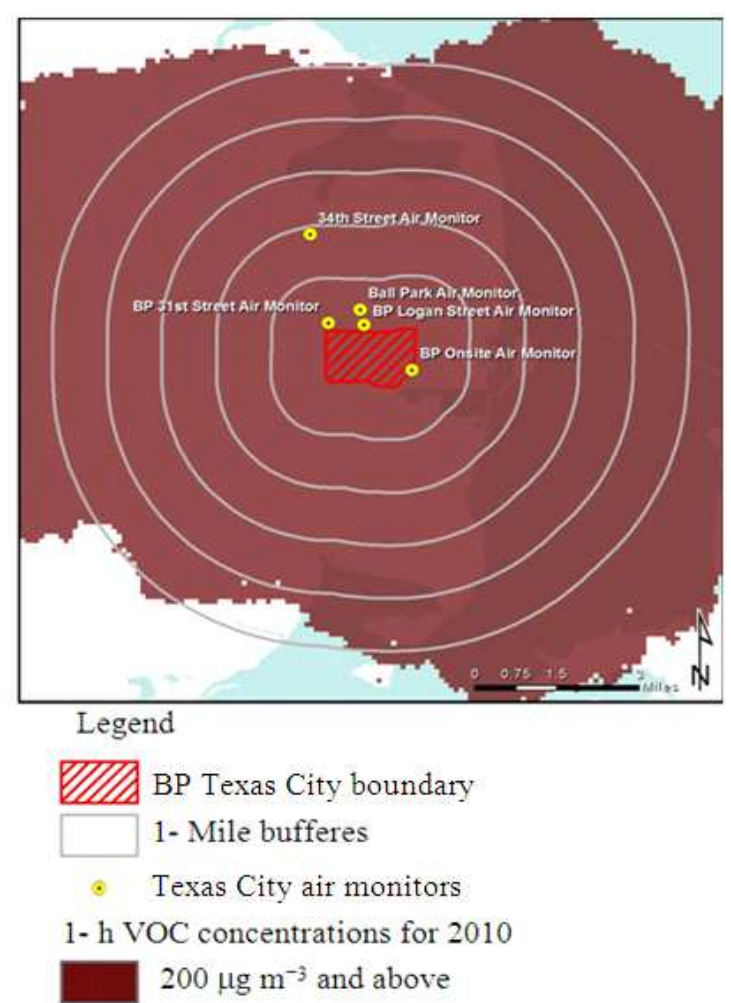

Fig. 6. 2010 1-hour ambient air concentration of VOCs in Texas City based on BP Texas City emissions

A number of published articles have shown that AERMOD is an accurate and reliable modeling system. Using empirical data in a variety of different scenarios, these studies showed that "estimated values agree with the observed concentrations within a factor of two" (Mohan et al., 2011). Moreover, AERMOD has consistently proven to be the most efficient of all the available air modeling systems, as well as produce the least amount of bias. Similarly, this study on BP facility emissions demonstrates the reliability of AERMOD.

Figure 7-11 show the air monitoring data for ozone, $\mathrm{SO} 2$ and VOCs respectively. Ozone has been included because its ambient air concentrations can be correlated to the concentrations of the other pollutants. The closest active ozone monitor to the facility is the Texas City 34th Street Monitor. The levels of ozone recorded by this air monitor have demonstrated exceedances of several regulatory thresholds over consecutive years in 2009 and 2010. Regulatory threshold exceedances for these years include the $1 \mathrm{~h}$ National Ambient Air Quality Standards (NAAQS) of $240 \mu \mathrm{g} \mathrm{m}^{-3}$ (120 ppbv), $8 \mathrm{~h}$ NAAQS of 150 $\mu \mathrm{g} \mathrm{m}^{-3}$ (75 ppbv) and the American Conference of
Governmental Industrial Hygienists (ACGIH) $8 \mathrm{~h}$ average Threshold Limit Value of $98.16 \mu \mathrm{g} \mathrm{m}{ }^{-3}$ (50 ppbv). SO2 concentrations measured by the Texas City Ball Park Monitor and several other air monitors exceeded the TCEQ Effects Screening Level (ESL) of $200 \mu \mathrm{g} \mathrm{m}^{-3}$ (75 ppbv) multiple times in 2009 and 2010. The $50 \mu \mathrm{g} \mathrm{m}^{-3}$ threshold exceedance demonstrated through air dispersion modeling of $\mathrm{SO} 2$ is supported by SO2 air monitoring data obtained from the aforementioned air monitoring stations, which frequently show exceedances above this threshold. Additionally, VOC concentrations in the form of pentane were detected by one of the Texas City air monitors (Logan Street) at concentrations exceeding $88.53 \mu \mathrm{g} \mathrm{m}^{-3}$ (30 ppbv) several times throughout 2010 (Fig. 9). Pentane concentrations for the year 2009 have been unavailable during this analysis and were therefore omitted.

Discrepancies between VOC concentrations demonstrated through air dispersion modeling and individual VOC concentrations observed within the air monitoring network highlights the capability of air dispersion modeling to more thoroughly characterize contaminant levels when the extent of the air monitoring system is inadequate. The air monitoring network currently utilized around the BP Texas City Refinery samples hourly at three locations for only four VOCs: Benzene, toluene, pentane and hexane. Yet these VOCs are not reflective of the quantity of unique VOCs being released from the facility. The air dispersion modeling software takes into account both classified and unclassified VOCs when developing a model for VOC exposure from facility emissions. The level of AERMOD's comprehensiveness concerning VOC exposure relative to the VOC sampling methods in the Texas City air quality monitoring network further demonstrates the accuracy and reliability of AERMOD as an emissions modeling tool.

It can be seen from the aforementioned figures that the SO2 AERMOD results are similar to concentrations detected by the air monitors. AERMOD results for VOCs demonstrate that contaminant levels in the community greatly exceed levels observed through air quality monitoring of individual VOCs. The discrepancy between the presumed community impact from VOC emissions shown through air monitoring data and the impact demonstrated through air dispersion modeling raises a unique concern regarding the cumulative impact of multiple VOCs. This concern is not apparent from data obtained through the air quality monitoring network, further demonstrating the accuracy and reliability of air dispersion modeling in evaluating community exposure to harmful contaminants. 
Joyce A. Chen et al. / American Journal of Environmental Science 8 (6) (2012) 622-632

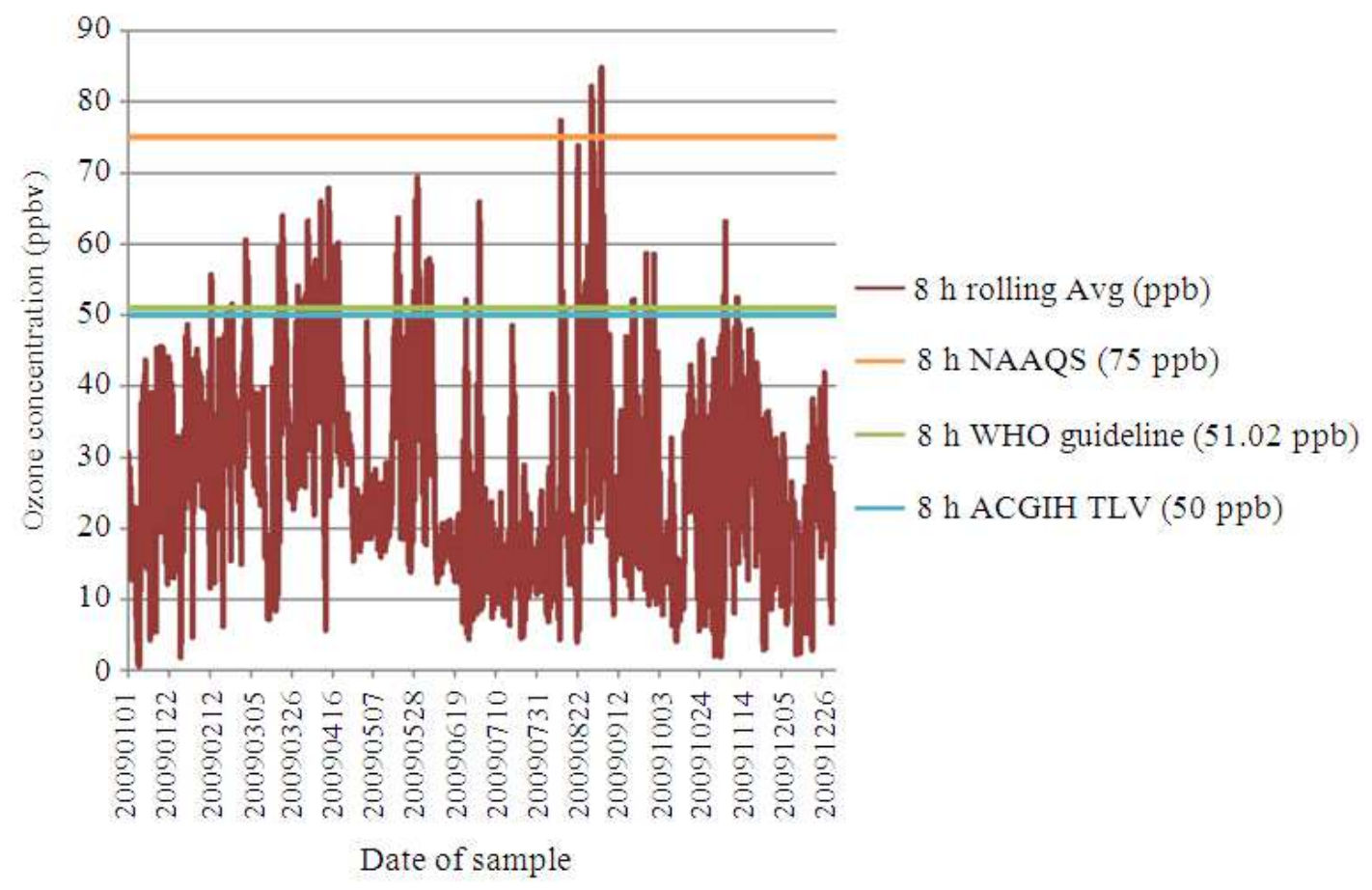

Fig. 7. 2009 Texas City 34th street air monitoring data for ozone, 8-hour rolling average concentrations

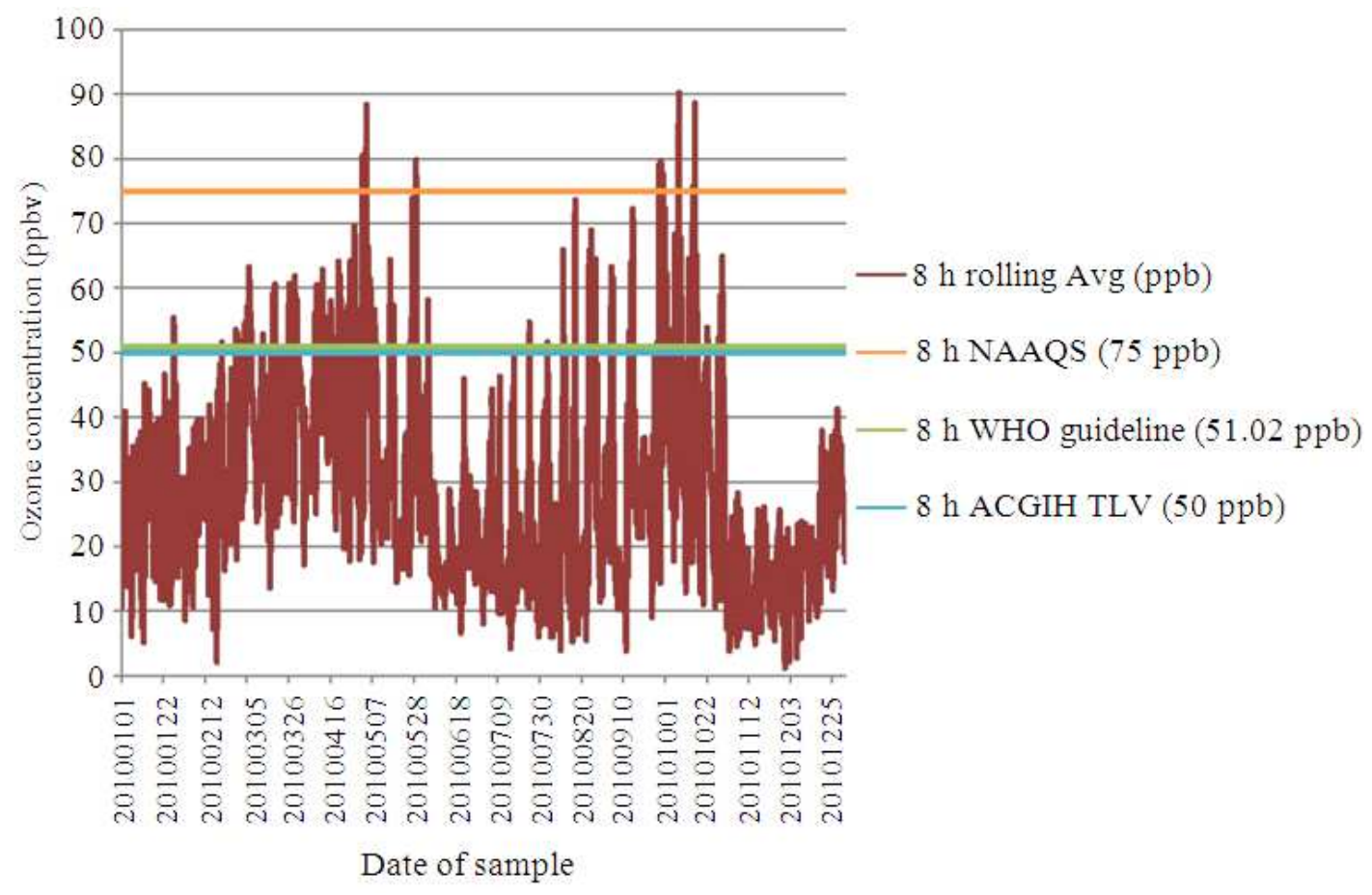

Fig. 8. 2010 Texas City 34th street air monitoring data for ozone, 8-hour rolling average concentrations 
Joyce A. Chen et al. / American Journal of Environmental Science 8 (6) (2012) 622-632

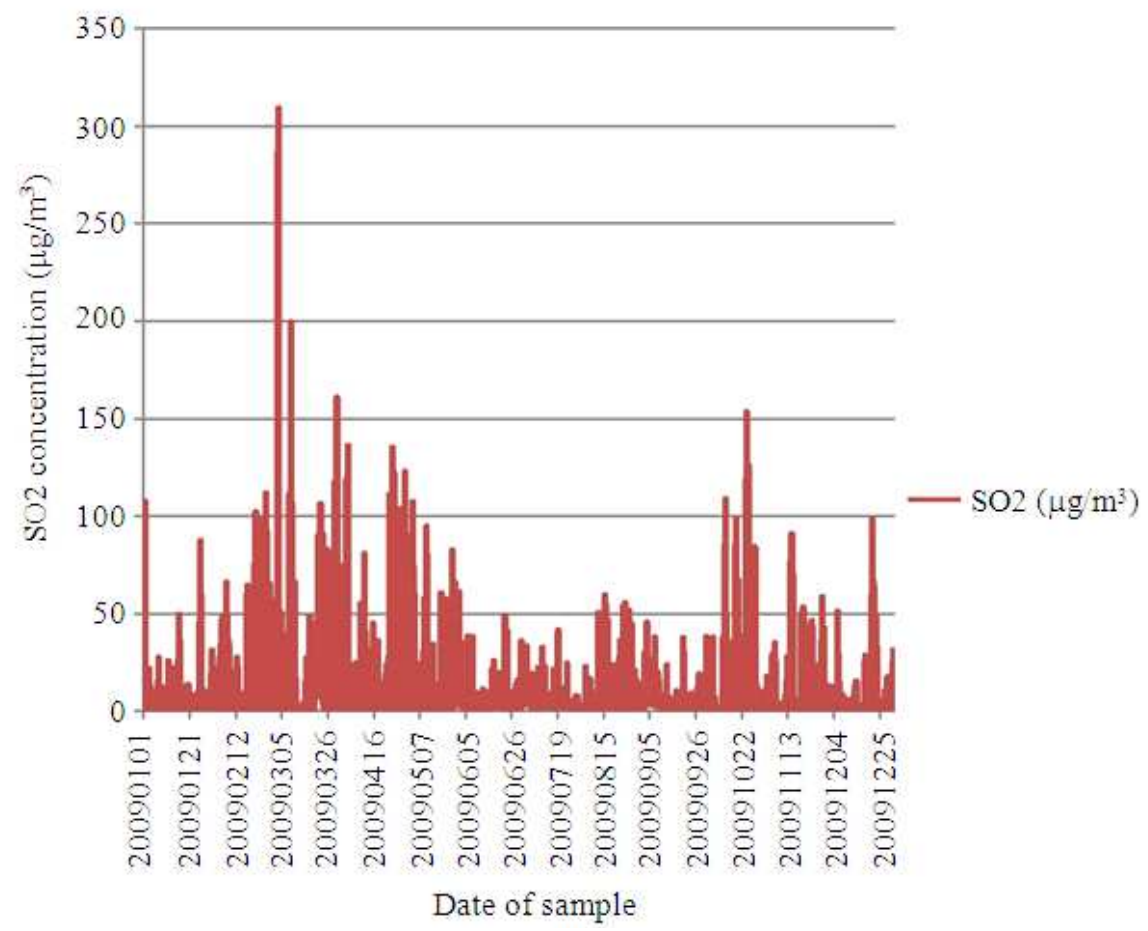

Fig. 9. 2009 Texas City Ball Park air monitoring data for SO2, 1-hour concentrations

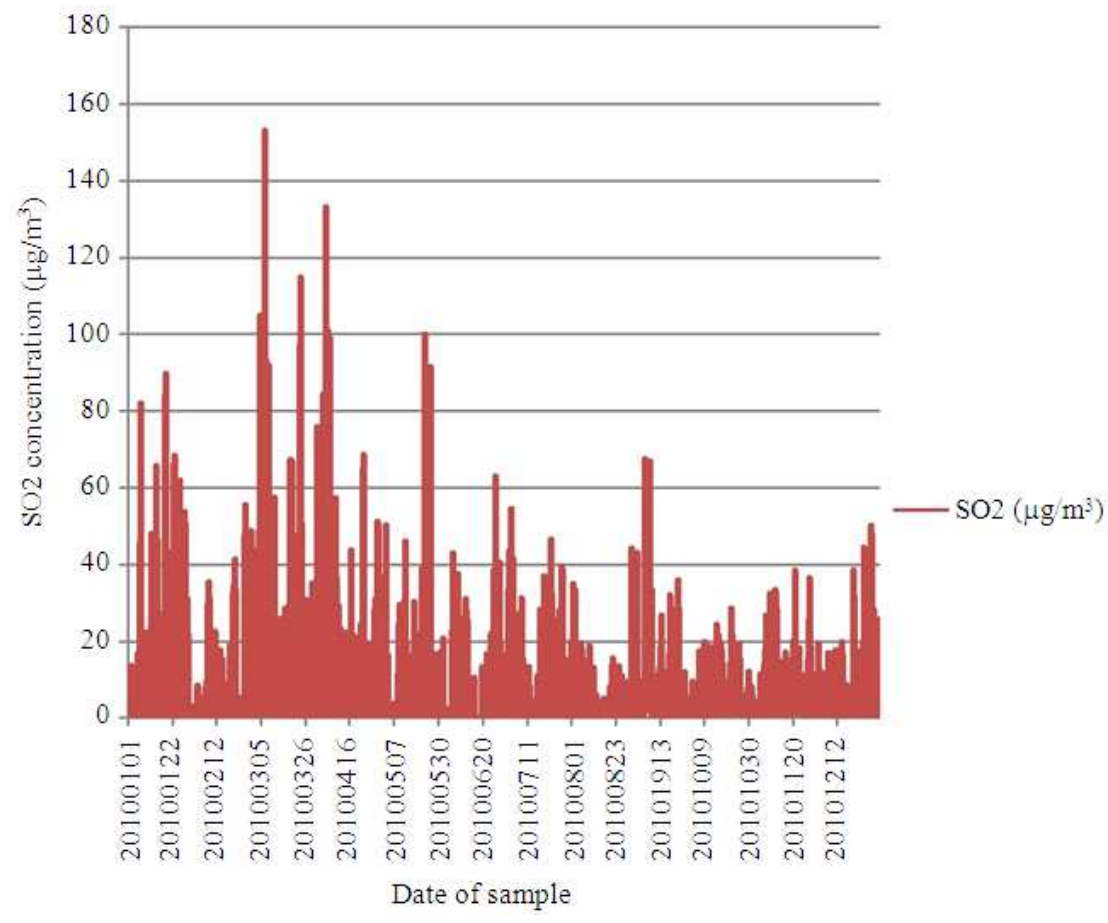

Fig. 10. 2010 Texas City Ball Park air monitoring data for SO2, 1-hour concentrations 
Joyce A. Chen et al. / American Journal of Environmental Science 8 (6) (2012) 622-632

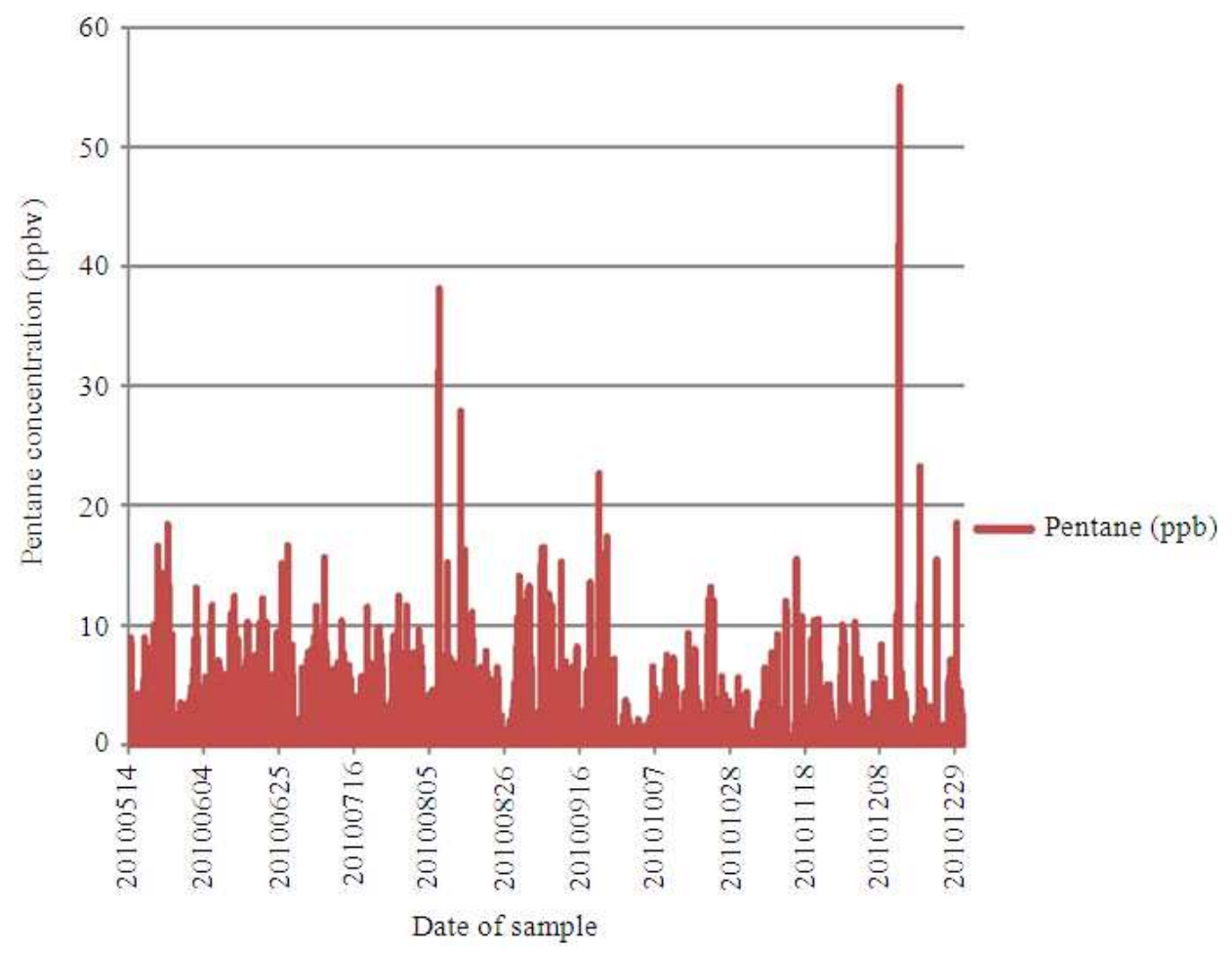

Fig. 11. 2010 Logan street air monitoring data for Pentane, 1-hour concentrations

\section{CONCLUSION}

BP Texas City Refinery, as one of the country's worst polluters, has released a variety of pollutants capable of spreading into neighborhoods in the Texas City area. Using AERMOD, the spatial extent of SO2 and VOC emissions from the BP facility was modeled in order to approximate their location and magnitude. The $\mathrm{SO} 2$ plume was based on $1 \mathrm{~h}$ concentrations of sulfur dioxide that reached or exceeded $50 \mu \mathrm{g} \mathrm{m}^{-3}$, a level which two peer-reviewed health studies demonstrated could double the risk of asthma attacks or exacerbation in sensitive children. All spatial locations inside this plume were affected by an incremental increase of $50 \mu \mathrm{g} \mathrm{m}^{-3}$ in $1 \mathrm{~h}$ ambient SO2 concentrations in 2009 and 2010. AERMOD was also used to model the extent of VOCs released from the BP facility. This analysis of SO2 concentrations in and around the BP facility produced results that correlated with those from the Texas City air monitoring system, thereby validating the usage of the AERMOD model. The comparison of the air dispersion modeling analysis for VOC exposure produced results that exceeded individual VOC detections observed from the air quality monitoring network, due to the fact that this modeling analysis incorporates a wider array of VOCs that are released from refinery operations than the air monitoring network takes into account.

\section{REFERENCES}

ATSDR, 1998. Public health statement for sulfur dioxide. Public Health Service, Atlanta, GA: U.S.

Chiu, H.F., M.H. Cheng and C.Y. Yang, 2009. Air pollution and hospital admissions for pneumonia in a subtropical city: Taipei, Taiwan. Inhalation Toxicol., 21: 32-37. DOI: 10.1080/08958370802441198

Delfino, R.J., H. Gong, W.S. Linn, Y. Hu and E.D. Pellizzari, 2003. Respiratory symptoms and peak expiratory flow in children with asthma in relation to volatile organic compounds in exhaled breath and ambient air. J. Exposure Anal. Environ. Epidemiol., 13: 348-363. DOI: 10.1038/sj.jea.7500287

Fung, K.Y., S. Khan, D. Krewski and Y. Chen, 2006. Association between air pollution and multiple respiratory hospitalizations among the elderly in Vancouver, Canada. Inhalation Toxicol., 18: 10051011. DOI: $10.1080 / 08958370600904538$ 
Luke, W.T., 1997. Evaluation of a commercial pulsed fluorescence detector for the measurement of lowlevel $\mathrm{SO}_{2}$ concentrations during the gas-phase sulfur intercomparison experiment. J. Geophys. Res., 102: 255-265. DOI: 10.1029/96JD03347

Mohan, M., S. Bhati, A. Screenivas and P. Marrapu, 2011. Performance evaluation of AERMOD and ADMS-urban for total suspended particulate matter concentrations in megacity Delhi. Aerosol Air Q. Res., 11: 883-894. DOI: 10.4209/aaqr.2011.05.0065

Segala, C., B. Fauroux, J. Just, L. Pascual and A. Grimfeld et al., 1998. Short-term effect of winter air pollution on respiratory health of asthmatic children in Paris. Eur. Respiratory J., 11: 677-685.

USEPA, 2008. Integrated Science Assessment (ISA) for sulfur oxides-health criteria. United States Environmental Protection Agency.

USEPA, 2009. Proposed revisions to the ambient air quality standards for sulfur dioxide. United States Environmental Protection Agency.
USEPA, 2010. Volatile organic compounds emissions. United States Environmental Protection Agency.

USEPA, 2012. An Introduction to Indoor Air Quality (IAQ) Volatile Organic Compounds (VOCs). United States Environmental Protection Agency.

Ware, J.H., J.D. Spengler, L.M. Neas, J.M. Samet and G.R. Wagner et al., 1993. Respiratory and irritant health effects of ambient volatile organic compounds. The Kanawha County Health Study. Am. J. Epidemiol., 137: 1287-1301. PMID: 8333411

Wieslander, G., D. Norback, E. Bjornsson, C. Janson and G. Boman, 1997. Asthma and the indoor environment: The significance of emission of formaldehyde and volatile organic compounds from newly painted indoor surfaces. Int. Arch. Occupat. Environ. Health, 69: 115-124. DOI: $10.1007 / \mathrm{s} 004200050125$ 